\title{
Dynamics of a two-module vibration-driven system moving along a rough horizontal plane
}

\author{
K. Zimmermann $\cdot$ I. Zeidis $\cdot$ N. Bolotnik $\cdot$ M. Pivovarov
}

Published online: 14 July 2009

(C) Springer Science+Business Media B.V. 2009

\section{Erratum to: Multibody Syst Dyn \\ DOI 10.1007/s11044-009-9158-2}

The first sentence in the second paragraph after equation (28) should read as follows:

The difference between the solution of the averaged equation (26) and the solution of (25) has an order of magnitude of $\varepsilon$ on the time interval of an order of $1 / \varepsilon$, provided that both sets of equations are subjected to the same initial conditions [36].

The online version of the original article can be found under doi:10.1007/s11044-009-9158-2.

K. Zimmermann · I. Zeidis $(\varangle) \cdot$ M. Pivovarov

Technische Universitaet Ilmenau, PF 1005 65, 98684 Ilmenau, Germany

e-mail: igor.zeidis@tu-ilmenau.de

K. Zimmermann

e-mail: klaus.zimmermann@tu-ilmenau.de

M. Pivovarov

e-mail: michail.pivovarov@ arcor.de

N. Bolotnik

Institute for Problems in Mechanics of the Russian Academy of Sciences, 101 bld. 1 Vernadskii ave.,

Moscow 119526, Russia

e-mail: bolotnik@ipmnet.ru 